serie Is financial instability male-driven? Gender and cognitive skills in experimental asset markets

WP-AD 2015-06 Carlos Cueva and Aldo Rustichini 
Los documentos de trabajo del Ivie ofrecen un avance de los resultados de las investigaciones económicas en curso, con objeto de generar un proceso de discusión previo a su remisión a las revistas científicas. Al publicar este documento de trabajo, el Ivie no asume responsabilidad sobre su contenido.

Ivie working papers offer in advance the results of economic research under way in order to encourage a discussion process before sending them to scientific journals for their final publication. Ivie's decision to publish this working paper does not imply any responsibility for its content.

La Serie AD es continuadora de la labor iniciada por el Departamento de Fundamentos de Análisis Económico de la Universidad de Alicante en su colección "A DISCUSIÓN" y difunde trabajos de marcado contenido teórico. Esta serie es coordinada por Carmen Herrero.

The AD series, coordinated by Carmen Herrero, is a continuation of the work initiated by the Department of Economic Analysis of the Universidad de Alicante in its collection "A DISCUSIÓN", providing and distributing papers marked by their theoretical content.

Todos los documentos de trabajo están disponibles de forma gratuita en la web del Ivie http://www.ivie.es, así como las instrucciones para los autores que desean publicar en nuestras series.

Working papers can be downloaded free of charge from the Ivie website http://www.ivie.es, as well as the instructions for authors who are interested in publishing in our series.

Versión: mayo 2015 / Version: May 2015

Edita / Published by:

Instituto Valenciano de Investigaciones Económicas, S.A.

C/ Guardia Civil, 22 esc. $21^{\circ}$ - 46020 Valencia (Spain) 
WP-AD 2015-06

\title{
Is financial instability male-driven? Gender and cognitive skills in experimental asset markets*
}

\author{
Carlos Cueva and Aldo Rustichini**
}

\begin{abstract}
The hypothesis that price stability would reliably increase with the fraction of women operating in financial markets has been frequently suggested in policy discussions. To test this hypothesis we conducted 10 male-only, 10 female-only and 10 mixed-gender experimental asset markets, and compared the effects of gender composition, confidence, risk attitude and cognitive skills. Male and female markets have comparable volatility and deviations from fundamentals, whereas mixed-gender markets are substantially more stable. On the other hand, higher average cognitive skills of the group are associated with reduced market volatility. Individual-level analysis shows that subjects with higher cognitive skills trade more rationally and earn significantly higher profits; similarly, mixed markets exhibit more rational behavior, particularly for traders with lower cognitive skills. Our results are demonstrated to hold in other experimental asset market studies, suggesting that a mixed-gender composition reduces mispricing across different types of asset markets.
\end{abstract}

Keywords: asset market experiment, mispricing, price bubbles, gender, cognitive ability.

JEL classification numbers: C91, C92, G02, G11, J16.

\footnotetext{
* We would like to thank Charles Noussair for discussions on the experimental design. Financial support from the UK Economic and Social Research Council, the Isaac Newton Trust and the Spanish Ministerio de Economía y Competitividad (ECO2012-34928) are gratefully acknowledged.

** C. Cueva: Universidad de Alicante. A. Rustichini: University of Minnesota, e-mail: rusti001@umn.edu (corresponding author).
} 


\section{Introduction}

Financial instability can have enormous economic consequences and is therefore a major concern for central banks and governments. The global financial crisis of 2008, triggered by the collapse of the US house price bubble, has led to a lasting global economic decline comparable to that of the Great Depression of the 1930s, which was itself also triggered by the burst of a US stock market bubble. Much of the current policy discussion in the US and the European Union has focused on reversing financial deregulation and imposing restrictions on incentive schemes in the finance industry such as bonus payments. It is argued that these policies may help to dampen the kind of excessive risk-taking that led to the crisis. Along similar lines, the fact that the majority of professional traders are men is being scrutinized: the idea that greater female participation could reduce reckless risk-taking and foster financial stability has received a great deal of attention in the media recently (Prügl, 2012). There are several reasons to suspect that greater female participation in financial markets may reduce the risk of bubbles and crashes. These relate to the evidence that, in specific contexts, women exhibit lower average risk-taking, overconfidence and competitiveness than men. ${ }^{1}$

Accounts of the "macho" culture of Wall Street traders in the 80s and 90s abound in the literature, but is this the case in present times? Recent evidence suggests that "machismo" continues to be a widespread problem in the finance industry which is likely discouraging female participation. $^{2}$ Furthermore, there is little evidence that gender balance has improved over the years in the sector. A survey of the percentage of female equity analysts at Wall Street brokerage firms found a drop from 16\% in 1996 to under 14\% in 2005 (Green et al., 2009), while the Bureau of Labor Statistics found that the number of young women entering the

\footnotetext{
${ }^{1}$ In a meta-analysis of 150 studies in sociology and psychology Byrnes et al. (1999) found a higher tendency for men to engage in risky behaviors in a broad range of contexts such as driving, physical activities, gambling, drug use or abstract choices. In economics, field studies have found that male households tend to choose riskier investment portfolios and pension plans (Bajtelsmit and VanDerhei, 1997; Jianakoplos and Bernasek, 1998; Sundén and Surette, 1998; Dwyer et al., 2002; Arano et al., 2010), and most laboratory experiments using incentivised choice tasks find gender differences consistent with the field evidence (Eckel and Grossman, 2008; Croson and Gneezy, 2009; Charness and Gneezy, 2012). Gneezy et al. (2003), Niederle and Vesterlund (2007), Datta Gupta et al. (2013) and Buser et al. (forthcoming) found that females are less motivated to compete for pay regardless of actual ability in the laboratory. These differences may be explained at least partly by the fact that men tend to be more overconfident in their own knowledge and ability (Deaux and Farris, 1977; Estes and Hosseini, 1988; Lundeberg et al., 1994; Soll and Klayman, 2004). However, the relationship between gender and competitiveness is likely context-specific. For instance, it has been found to vary across cultures and tasks (Gneezy et al., 2009; Günther et al., 2010; Dreber et al., 2011; Cárdenas et al., 2012; Shurchkov, 2012), and evidence suggests that stereotype-threat could be a key driver of female underperformance (Iriberri and ReyBiel, 2013). See Croson and Gneezy (2009), Bertrand (2011) and Niederle and Vesterlund (2011) for reviews and discussions.

${ }^{2}$ See for instance, a 2013 survey by the Financial Times discussed here: http://www.ft.com/cms/s/0/ 3ee96d7c-52a2-11e3-8586-00144feabdc0.html
} 
finance industry dropped more than $16 \%$ between 2000 and 2009 compared to a $7.3 \%$ rise in young male participation. The U.S. Equal Employment Opportunity Commission found that in 2012 women made up only $15.6 \%$ of executive or senior-level officials and managers at companies surveyed under the category "Investment Banking and Securities Dealing". Interestingly, recent evidence suggests that biology may also play a role in the predominance of men in the finance industry: testosterone, a steroid hormone present in much higher concentrations in men than in women, was positively associated with performance and endurance in the high frequency trading business (Coates and Herbert, 2008; Coates et al., 2009), and with the likelihood of choosing a career in finance (Sapienza et al., 2009). These latter findings, perhaps combined with an acute public interest in the sources of financial instability, have fueled the folk hypothesis that overconfident, risk-loving and cut-throat competitive men are to blame for the dramatic financial turmoil of the last few years.

We address the conjecture that gender composition of the market influences price stability: we do this by studying the stability of experimental asset markets with different gender composition. This approach has two key advantages. First, it allows us to address a hypothetical question which cannot be answered in the field. Several studies have looked at gender differences in trading in the field, ${ }^{3}$ but their findings are unreliable if we are interested in predicting how markets would behave if its gender composition was dramatically different. For instance, peer effects might play an important role, so that women in a male-dominated market could behave differently than in a female dominated market. Also, women who choose careers in finance and succeed in the sector are a highly selected sample which may currently be biased in favor of those with most stereotypically male attitudes towards risk-taking, confidence and competitiveness. Secondly, our experimental markets have known and constant fundamentals, so, unlike in the field, we are able to measure precisely the extent to which prices deviate from fundamentals and thus assess the impact of gender composition on mispricing and stability. Finally, we investigate the size of this hypothetical effect in relation to other relevant characteristics of the market, such as cognitive skills, risk aversion and confidence levels. The asset markets were conducted

\footnotetext{
${ }^{3}$ Barber and Odean (2001) provide evidence of overtrading in male household owners of a brokerage account but not of female owners. Grinblatt and Keloharju (2009) analyzed equity trading data from Finnish investors and found that women made substantially fewer trades than men at all age levels. Grinblatt and Keloharju (2001) analyzed investors' buys, sells and holds and found a higher propensity to buy in men. Beckmann and Menkhoff (2008) surveyed fund managers and found greater risk aversion and lower willingness to compete of female managers. Atkinson et al. (2003) found no risk differences in fund managers' investment behavior but lower net inflows into accounts managed by women. In this line, Madden (2012) found that female brokers perform equally well but receive lower quality accounts than male brokers.
} 
in an open-plan room, so that participants could observe the gender composition of the market.

Our results contradict the conjecture that markets entirely composed of female traders are more stable than those entirely composed of male traders. Both types of markets were comparably and substantially unstable in our experiments. On the other hand, mixed-gender markets were significantly more stable, exhibiting surprisingly small deviations of prices from fundamental values. These results also hold after controlling for risk aversion, confidence and cognitive skills (CS). Novelly, CS turned out to be a strong predictor of aggregate market stability.

We conjecture that a mixed-gender composition reduced reckless trading by dampening excessive competitive behavior that is induced in single-gender environments. This conjecture is based on previous evidence that single-gender environments result in more agressive and inefficient bargaining (Holm, 2000; Sutter et al., 2009; Castillo et al., 2013), and increase competitiveness and willingness to take risks (Gneezy et al., 2003; Gneezy and Rustichini, 2004; Booth and Nolen, 2012a,b; Booth et al., 2014).

When we consider individual characteristics we found that CS was a strong predictor of earnings and trading rationality. Trading patterns also indicated substantial learning by traders with lower CS. Traders employed strategies much closer to the rational expectations equilibrium benchmark in mixed-gender markets, which consequently exhibited substantially lower variance in earnings. Our analysis suggests that a mixed-gender composition of the market attenuated the destabilizing effect of lower CS traders.

Our study is closely related to contemporaneous work by Eckel and Füllbrunn (2015), who conclude that male-only markets are more prone to bubbles than female-only markets. Even though female-only markets produced fewer and smaller bubbles in their experiments, they exhibited as severe mispricing as male-only markets, and higher trading volumes. Eckel and Füllbrunn also reviewed 35 studies using a similar market design and found a negative correlation between bubble magnitude and the proportion of women in the market. We analyzed this data and found that mixed-gender markets also exhibited significantly lower mispricing than single-gender markets. Their experimental design follows closely that of Smith et al. (1988), in which assets have a declining (rather than constant) fundamental value. Baring the differences in experimental design, our results are remarkably compatible with those reported in Eckel and Füllbrunn (2015), and suggest that a mixed-gender composition reduces mispricing across different types of experimental asset markets. 
In section II we outline our experimental design, in section III we state our main results and various indivual-level findings, and in section IV we discuss our results.

\section{Experimental Design}

\section{A Experimental procedure}

A total of 284 men and women participated in this study (men: $\mathrm{N}=141$, mean age $( \pm$ s.d.) $=$ $22.22 \pm 3.55$; women: $\mathrm{N}=143$, mean age $( \pm$ s.d. $)=22.74 \pm 3.48)$. We conducted 10 femaleonly sessions, 10 mixed-gender sessions, and 10 male-only sessions. The experiment room was open-plan, so that participants could observe the gender composition of the group. We did not remark or make this feature salient in any way; for instance, the invitation emails targeted male and female volunteers separately, but did not mention any gender requirements. Market size was typically of 10 traders and most mixed-gender sessions were composed of 5 male and 5 female participants. ${ }^{4}$ All participants provided written consent to the study, previously approved by the local ethics committee. Participants were students at the University of Cambridge. All experiments were conducted at the experimental laboratory of the Faculty of Economics at the University of Cambridge. Each volunteer participated in one session only, which lasted $2 \mathrm{~h}$ approximately. A session consisted of 3 tasks in this order: lottery task, trading task (asset market) and cognitive skills tasks. Participants were paid on average 20 GBP $(\approx 33$ U.S. dollars). They were handed printed instructions for each task and had the opportunity to ask the experimenter to clarify any doubts throughout the session.

\section{B Asset market}

Markets were conducted using a computerized double auction mechanism based on a design by Noussair et al. $(2001)^{5}$. There were 15 trading periods in total, plus an additional practice period at the beginning. Each subject was initially endowed with 10 assets and a 10,000 francs loan. Assets paid either $-24,-16,4$ or 36 "francs" with equal probability at the end of every period, plus a maturity value of 360 francs at the end of period 15. Since dividends every period had zero expected value, the fundamental value of the asset was constant at 360 francs. This

\footnotetext{
${ }^{4}$ In some cases where several participants did not show up, sessions were conducted with less than 10 participants or with an uneven gender mix, see Table A.II in the appendix.

${ }^{5}$ Their design was, in turn, a variation of the classic design by Smith et al. (1988), which has been used extensively to study the properties of price bubbles in the laboratory, see Porter and Smith (2003) and Palan (2013) for reviews.
} 
was clearly explained in the instructions, so that the fundamental value of the asset was known. Francs had a conversion value of 360 francs $=1$ GBP. Therefore, subjects would earn on average 10 GBP $(\approx 17$ U.S. dollars) in this task. In order to maintain total available cash in the market constant, dividends were not added to subjects' payoffs until the end.

The market operated with an "open book": all bids and asks submitted during a trading period were listed on subjects' screens, anonymously and ordered by price. A subject could accept any number of bids or asks provided he or she had sufficient funds to complete the transaction. Each trading period lasted 2 minutes. During trading, subjects could see all outstanding bids and asks in the market, all concluded transaction prices for that period, their current cash and asset holdings, and a plot of average transaction prices in every past period. At the end of a trading period dividends for that period were announced. These were the same for every asset in the market. Subjects were also provided with a summary of their total cash, assets and dividends up to that period. Before the new trading period began, subjects were asked to make a guess about the average transaction price in the next period. Each accurate guess was rewarded with an extra 10 pence at the end of the session.

To check that participants had understood the task correctly, they were asked to complete a 6-item questionnaire about the trading task. Subjects making any mistakes in the questionnaire were approached individually so that any misunderstandings could be verbally addressed.

\section{C Other measures}

Before conducting the asset market, we measured risk aversion using a lottery task based on a simplified version of the Holt and Laury method (Holt and Laury, 2002; Sapienza et al., 2009). A total of 15 binary choices were simultaneously presented on subjects' screens, who could take as much time as they wished to complete and review all 15 decisions. For each subject, one of the choices would be randomly selected with equal probability at the end of the experiment for payment. Table A.I in the appendix displays the list of choices.

After the asset market, we measured cognitive skills using two different tasks, referred to in the instructions as "hit-15" and "pattern" tasks. Hit-15 is a competitive game played against the computer solvable by backward induction (Burks et al., 2009). The task is designed to test planning ability and strategic thinking. The pattern task is a subset of Raven's advanced progressive matrices, set II (Raven, 2000). These matrices are widely used as a standard nonverbal IQ test. Each round won in hit-15 and correct pattern in the second task was rewarded 
with 50 pence.

Before and after every task except the lottery, participants were asked to make a guess about their own performance. They were rewarded an extra 50 pence every time their guesses were within $10 \%$ of the true answer. Two different measures of confidence were used: an absolute measure which consisted of a subject's guess about the score obtained in a given task, and a relative measure, consisting of a subject's guess about his or her percentile rank in the group.

\section{Results}

\section{A Market stability}

The stability of markets varied substantially depending on the gender composition. Figure I shows median transaction prices by period in every market, grouped according to their gender composition. All markets are otherwise identical. Crucially, the fundamental value of an asset in these markets is known and constant at 360. If all traders act rationally and this is common knowledge, prices should not significantly depart from 360 in these markets. Visual inspection reveals that mixed-gender markets display much smaller deviations of prices from the fundamental value than female-only or male-only markets and that the two markets with the most extreme departures from fundamentals were female-only markets. To quantify the degree of price instability in these markets we used a standard measure called amplitude (Porter and Smith, 2003). Formally: Amplitude $=\left(\max _{t \in T}\left(P_{t}\right)-\min _{t \in T}\left(P_{t}\right)\right) / F$; where $P_{t}$ is the median transaction price at period $t, T$ is the set of 15 periods, and $F$ is the fundamental value of the asset. That is, amplitude is the difference between the maximum and minimum median transaction price observed in a market divided by the fundamental value of the asset, where median transaction prices are calculated for each trading period. Pairwise comparisons using Mann-Whitney $U$-tests confirm a large and significant difference in amplitude between homogeneous gender and mixed-gender markets, and no difference between female-only and male-only markets (female-only vs. mixed-gender: $p=0.016$; male-only vs. mixed-gender: $p=0.013$; female-only vs. male-only: $p=0.910) .{ }^{6}$ There are other measures which have often been used

\footnotetext{
${ }^{6}$ The Mann-Whitney $U$-test is a non-parametric test appropriate for small sample comparisons. Furthermore, its statistic is a sum of ranks and is therefore robust to outliers. Nonetheless, we checked whether our result could be driven by outliers, and compared amplitude in homogeneous gender markets and mixed-gender markets after excluding the three markets with the highest amplitude (2 female-only markets and 1 male-only market). Pairwise comparisons still confirm a significant difference in amplitude between homogeneous gender and mixedgender markets, and no difference between female-only and male-only markets (female-only vs. mixed-gender: $p=0.050 ;$ male-only vs. mixed-gender: $p=0.022$; female-only vs. male-only: $p=0.736$ )
} 
Table I: Market measures, averaged for female-only, male-only and mixed-gender markets. Between-sessions standard deviations shown in parentheses.

\begin{tabular}{|c|c|c|c|c|c|}
\hline Market measure & Female-only & Male-only & mixed-gender & $\begin{array}{c}\text { female-only } \\
\text { vs. } \\
\text { male-only } \\
\text { (p-value)* }\end{array}$ & $\begin{array}{c}\text { homogeneous gender } \\
\text { vs. } \\
\text { mixed-gender } \\
\text { (p-value })^{*}\end{array}$ \\
\hline Turnover & $\begin{array}{c}3.27 \\
(0.92)\end{array}$ & $\begin{array}{c}2.50 \\
(0.75)\end{array}$ & $\begin{array}{c}2.57 \\
(0.83)\end{array}$ & 0.049 & 0.482 \\
\hline Amplitude & $\begin{array}{c}0.14 \\
(0.17)\end{array}$ & $\begin{array}{c}0.10 \\
(0.09)\end{array}$ & $\begin{array}{c}0.03 \\
(0.02)\end{array}$ & 0.910 & 0.004 \\
\hline NAD & $\begin{array}{c}1.01 \\
(1.19)\end{array}$ & $\begin{array}{c}0.69 \\
(0.61)\end{array}$ & $\begin{array}{c}0.31 \\
(0.36)\end{array}$ & 0.821 & 0.031 \\
\hline Dispersion & $\begin{array}{c}0.07 \\
(0.09)\end{array}$ & $\begin{array}{c}0.06 \\
(0.04)\end{array}$ & $\begin{array}{c}0.03 \\
(0.02)\end{array}$ & 0.597 & 0.059 \\
\hline Bias & $\begin{array}{c}0.05 \\
(0.09)\end{array}$ & $\begin{array}{c}0.05 \\
(0.03)\end{array}$ & $\begin{array}{c}0.03 \\
(0.02)\end{array}$ & 0.174 & 0.253 \\
\hline RAD & $\begin{array}{c}0.06 \\
(0.07)\end{array}$ & $\begin{array}{c}0.06 \\
(0.03)\end{array}$ & $\begin{array}{c}0.02 \\
(0.02)\end{array}$ & 0.450 & 0.039 \\
\hline $\mathrm{RD}$ & $\begin{array}{c}0.03 \\
(0.08)\end{array}$ & $\begin{array}{c}0.05 \\
(0.03)\end{array}$ & $\begin{array}{c}0.02 \\
(0.02)\end{array}$ & 0.199 & 0.333 \\
\hline 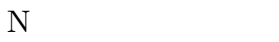 & 10 & 10 & 10 & & \\
\hline
\end{tabular}

Note: These are measures commonly used to measure the degree of mispricing in experimental asset markets, see for instance Stöckl et al. (2010). Turnover $=\sum_{t=1}^{T}$ transactions $t / A$; Amplitude $=\left(\max _{t}\left(P_{t}\right)-\min _{t}\left(P_{t}\right)\right) / F$; Normalized (absolute) deviation, $N A D=\sum_{t=1}^{T} \sum_{i}^{I_{t}} \mid$ price $_{i, t}-F \mid /(100 \times A)$; Dispersion $=\sum_{t=1}^{T}\left|P_{t}-F\right| /(F \times T)$; Bias $=\sum_{t=1}^{T}\left(P_{t}-F\right) /(F \times T)$; Relative absolute deviation, $R A D=\sum_{t=1}^{T}\left|\bar{P}_{t}-F\right| /(F \times T)$; Relative deviation, $R D=\sum_{t=1}^{T}\left(\bar{P}_{t}-F\right) /(F \times T)$ where transactions $t$ is the total number of transactions executed in period $t, T$ is the total number of trading periods in the market $(T=15), A$ is the total number of assets in the market, $P_{t}$ is the median transaction price at period $t, \bar{P}_{t}$ is the (volume weighed) average transaction price at period $t, F$ is the fundamental value of the asset $(F=360), I_{t}$ is the total number of transactions executed in period $t$, and price $_{i, t}$ is the price of the $i^{\text {th }}$ transaction executed in period $t$.

to quantify market volatility and mispricing (see Stöckl et al., 2010). We list the most relevant variables and the results from pairwise comparisons between treatments in Table I.

Two main results emerge from the data displayed in Table I. Firstly, male-only and femaleonly markets are comparable in all measures of mispricing with the exception of turnover, which is higher in female-only markets. Even though turnover is not a measure of mispricing per se, large price deviations from fundamentals tend to be accompanied by high turnover. Together, these results reject the notion that female-only markets are more stable than maleonly markets. Secondly, mixed markets exhibit significantly lower absolute deviations of prices from fundamentals and lower amplitude than homogeneous-gender markets.

We evaluated the possible effect of other relevant characteristics of the market, and compared it with gender composition. We did this by estimating a log-linear regression model of amplitude as a function of average risk aversion, confidence, gender composition and cognitive skills $(C S)$ 

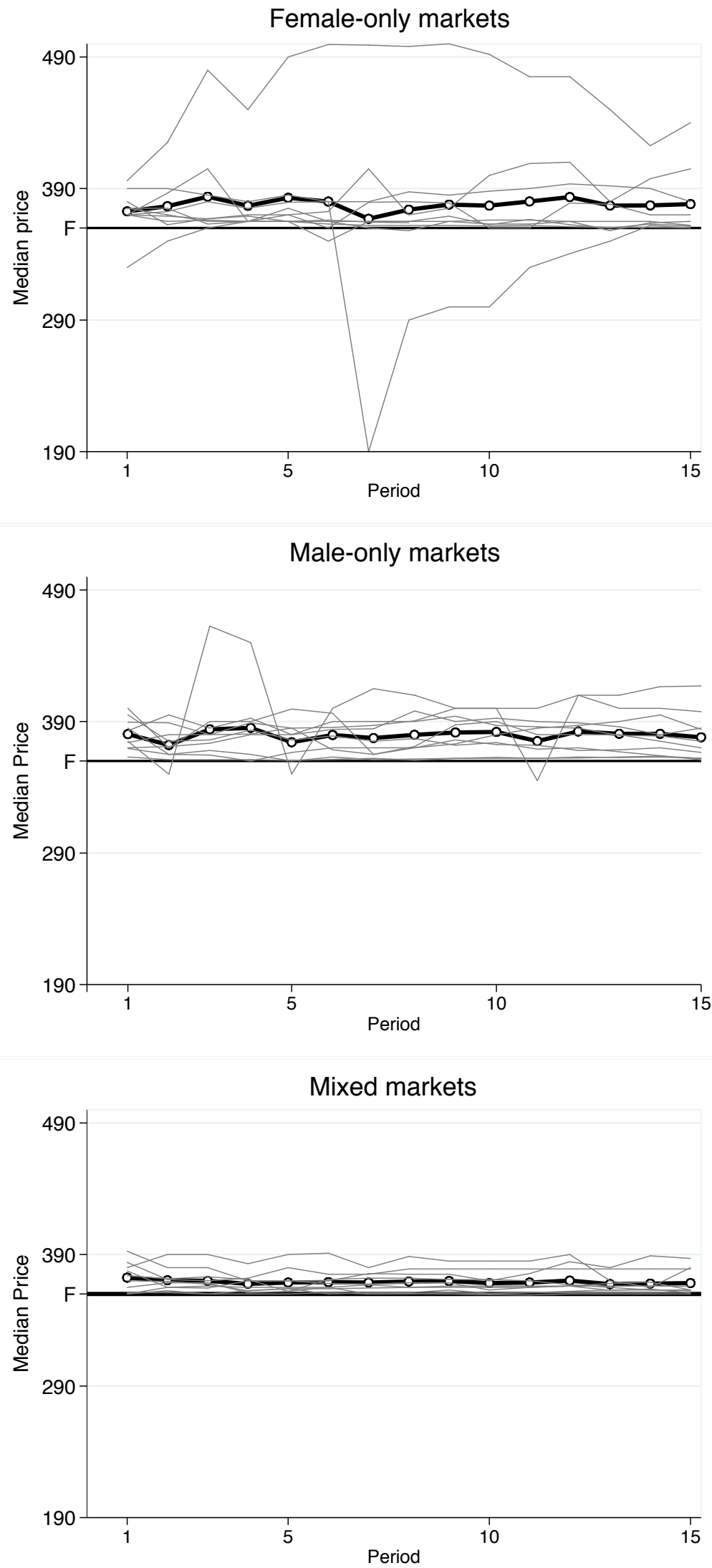

Figure I: Median transaction prices in each market. Markets are grouped into each panel according to their gender composition. Bold line displays group average. $\mathrm{F}=$ Fundamental value 
Table II: OLS Estimates of Amplitude (log-transformed, $\mathrm{N}=30$ ). Bootstrapped std. errors using 1000 replications

\begin{tabular}{lccc}
\hline \hline $\begin{array}{l}\text { Dep. Variable: Amplitude } \\
\text { (log-transformed) }\end{array}$ & $\begin{array}{c}\mathbf{1} \\
\text { Coefficient } \\
\text { (Std. Error) }\end{array}$ & $\begin{array}{c}\mathbf{2} \\
\text { Coefficient } \\
\text { (Std. Error) }\end{array}$ & $\begin{array}{c}\mathbf{3} \\
\text { Coefficient } \\
\text { (Std. Error) }\end{array}$ \\
\hline female-only & 0.270 & -0.013 & -0.059 \\
& $(0.502)$ & $(0.386)$ & $(0.340)$ \\
mixed-gender & $-0.830^{*}$ & $-0.923^{* *}$ & $-0.946^{* *}$ \\
& $(0.325)$ & $(0.331)$ & $(0.350)$ \\
CS & $-5.902^{* * *}$ & $-5.647^{* *}$ & $-5.544^{* *}$ \\
& $(1.624)$ & $(1.776)$ & $(1.737)$ \\
risk aversion & -0.318 & -0.184 & \\
& $(0.641)$ & $(0.655)$ & \\
confidence & 4.150 & & 30 \\
\multirow{2}{*}{$N$} & $(2.626)$ & & \\
\hline$* p<0.05,{ }^{* *} p<0.01,{ }^{* * *} p<0.001$ & & & \\
\end{tabular}

of the market. ${ }^{7}$ Results show that gender composition and $C S$ were highly significant predictors of amplitude, whereas risk aversion and confidence were not. Controlling for the other factors, mixed markets had around $60 \%$ less amplitude than homogeneous gender markets. Similarly, a $10 \%$ increase from the mean in $C S$ of the market predicts a $30 \%$ reduction in amplitude. A more substantial increase in $C S$, say, of $25 \%$ from the mean (two standard deviations in our data), would lead to a reduction in amplitude of around $60 \%$ (see Table II).

An important feature of bubbles or other instances of severe mispricing is that they can lead to dramatic redistributions of wealth. It is therefore interesting to examine the effect of gender composition on the final distribution of wealth. As can be seen in Figure II, the dispersion of trading profits varied substantially with gender composition of the market. For instance, around $10 \%$ of traders in female-only or male-only markets lost at least half of their initial endowment by the end of the market, whereas this was the case for only $3 \%$ of traders in mixed-gender markets. In fact, dispersion of trading profits was highest in female-only markets and lowest in mixed-gender markets: a Brown-Forsythe test rejects the null hypothesis of no difference in variance of final trading profits between female-only and mixed markets $(p=0.021)$ and between female-only markets and male-only markets $(p=0.048)$, but not between male-only markets and mixed markets $(p=0.513)$.

In sum, our analysis of aggregate market stability rejects the hypothesis that male-only markets are more unstable than female-only markets. All measures of mispricing and instability

\footnotetext{
${ }^{7}$ Risk aversion was measured as a subject's risk premium based on his or her choices of lotteries. We aggregated the scores on the hit-15 and the pattern tasks for each subject into a single measure of $C S$. Since we had no prior over the relative predictive power of one measure over the other, we gave them equal weight and computed it as the (weighted) average score in the two tasks, normalized between 0 and 1 . Confidence was measured as the percentile rank guessed by the subject before trading (normalized between 0 and 1 ).
} 
are similar across the two treatments and female-only markets exhibited higher turnover and variance in earnings.

Two additional results emerged from the aggregate analysis: higher average CS in the market strongly decreased mispricing, and, surprisingly, so did a mixed-gender composition. In the next section we attempt to shed light on these aggregate findings.

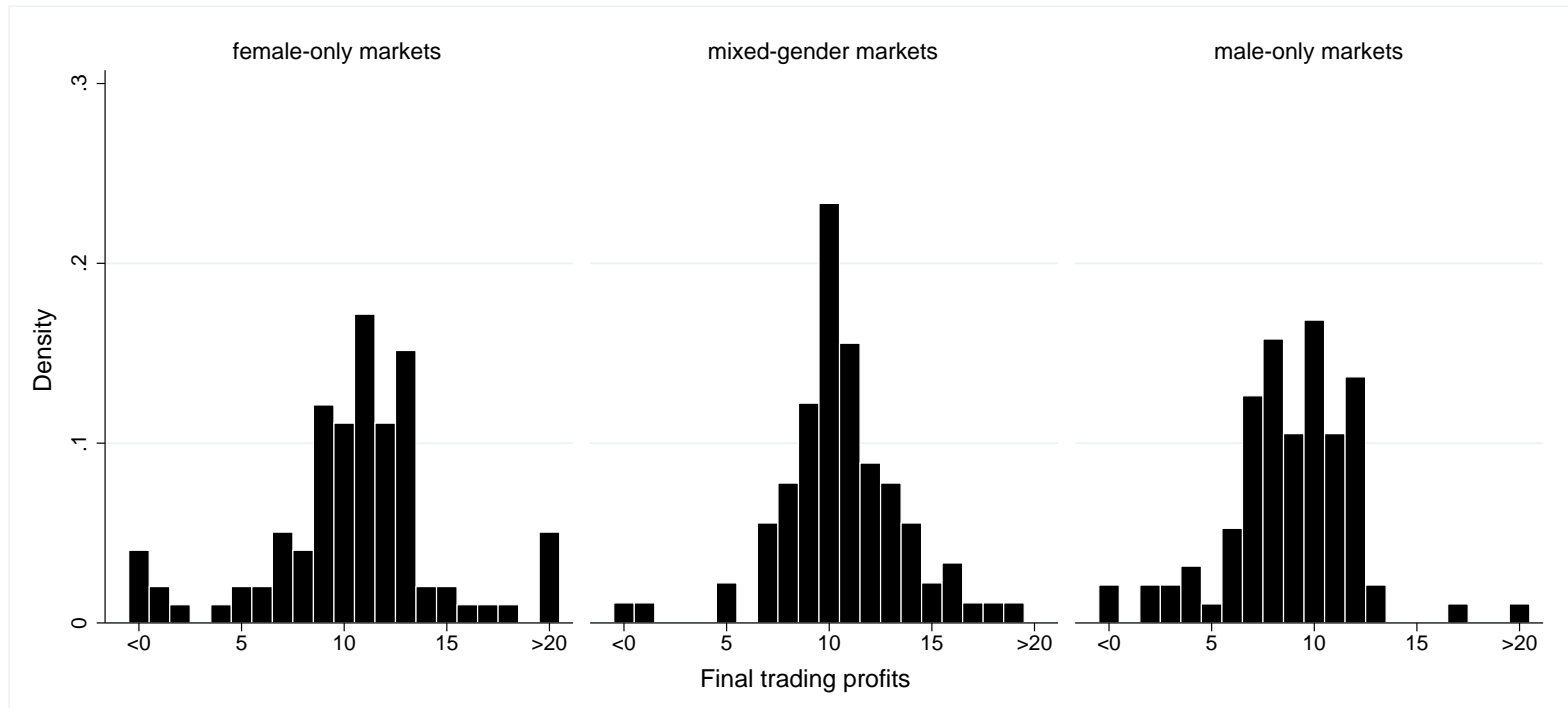

Figure II: Histogram of subjects' final trading profit in each treatment.

\section{B Why are mixed-gender markets more stable?}

To understand the impact of gender composition on market stability, we investigated individual trading performance in a dynamic setting. We define the variable tradegain, which measures a trader's profits from sales and purchases in each period, as:

$$
\operatorname{tradegain}_{i, t}=\sum_{j}\left(\operatorname{sale}_{i, t}^{j}-F\right)+\sum_{k}\left(F-\operatorname{purchase}_{i, t}^{k}\right)
$$

where $s a l e_{i, t}^{j}$ and purchase $e_{i, t}^{k}$ are the selling and buying prices of the $j^{t h}$ and $k^{t h}$ transaction executed by trader $i$ in period $t$.

As shown in Figure III, gender composition and crucially CS had a big effect on the dispersion of tradegain at the start of the market. There were large transfers of wealth from low $C S$ subjects to high $C S$ subjects in single-gender markets at the early stages, and the effect was much more attenuated in mixed-gender markets. The difference in performance gradually decreased between high and low CS subjects, likely due to learning by low CS traders.

Estimation results in Table III confirm that tradegain was strongly influenced by $C S$, and 


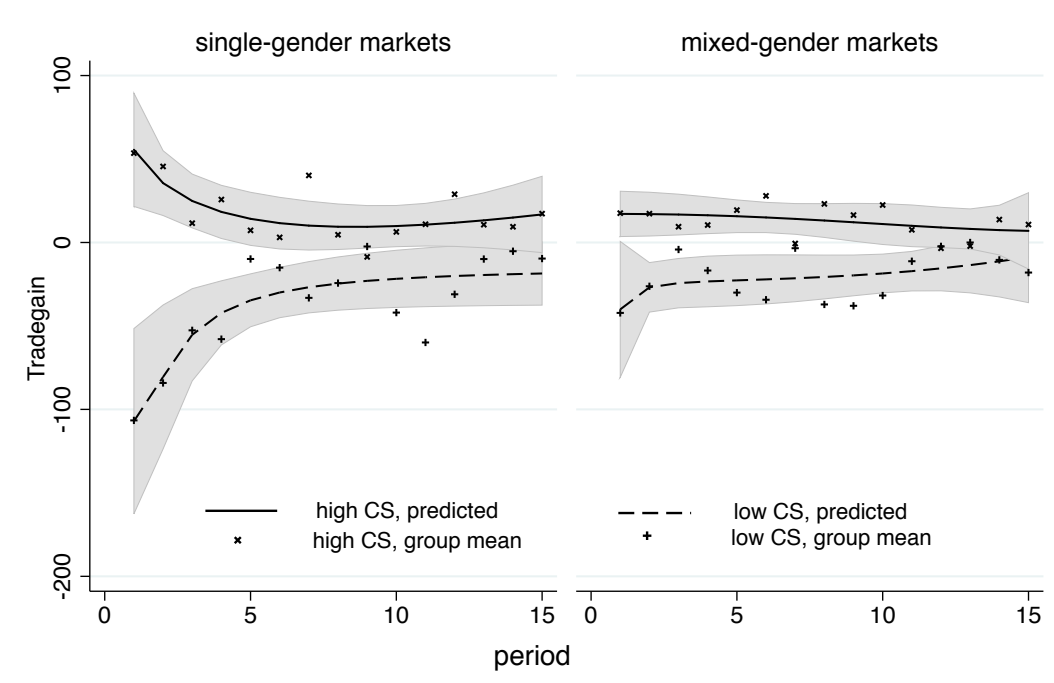

Figure III: Tradegain over time for traders with CS scores in the top and bottom third of our sample. Curves fitted from fractional polynomial regressions of trade gain on period, shaded areas are $99 \%$ confidence intervals.

not by gender. Specifically, there was no significant difference in performance between male and female traders in mixed markets, whereas traders with higher $C S$ outperformed traders with lower $C S$. Learning effects were also strong: as the market progressed, high and low $C S$ traders reduced the gap in performance, although not completely.

Examination of Figure III suggests that a mixed-gender environment may moderate the destabilizing effect of low $C S$ traders in the market. We checked this possibility by analyzing the amount of mispricing incurred by low CS and high CS traders in single-gender and mixedgender markets. We defined mispricing as the normalized sum of a subject's purchases above the fundamental value and sales below the fundamental value, that is:

$$
\text { mispricing }_{i}=\frac{1}{T \times F}\left(\sum_{j}\left(\text { purchase }_{i}^{j}-F \mid \text { purchase }_{i}^{j}>F\right)+\sum_{k}\left(F-\text { sale }_{i}^{k} \mid \text { sale }_{i}^{k}<F\right)\right)
$$

so if a subject never purchases an asset at a price greater than its fundamental value or sells at a price below the fundamental value, then mispricing takes value zero for that subject.

Table IV summarizes the results, which support our interpretation. Low CS subjects (defined as subjects with CS scores in the bottom third of our sample) exhibit significantly lower mispricing in mixed-gender markets than in single-gender markets. The effect is strong and sig- 
Table III: Random Effects Panel Regression Estimation of tradegain. Std. errors adjusted for 30 clusters (one for each market).

\begin{tabular}{lccc}
\hline \hline Dep. var: tradegain & $\begin{array}{c}\text { Coef. } \\
\text { (std. error) }\end{array}$ & $\begin{array}{c}\text { Coef. } \\
\text { (std. error) }\end{array}$ & $\begin{array}{c}\text { Coef. } \\
\text { (std. error) }\end{array}$ \\
\hline$C S$ & $238.012^{* *}$ & $224.715^{* *}$ & $224.879^{* *}$ \\
& $(82.420)$ & $(70.115)$ & $(70.204)$ \\
period & $7.056^{* * *}$ & $7.060^{* * *}$ & $7.060^{* * *}$ \\
& $(2.042)$ & $(2.041)$ & $(2.041)$ \\
$C S \times$ period & $-10.665^{* * *}$ & $-10.672^{* * *}$ & $-10.672^{* * *}$ \\
& $(3.133)$ & $(3.132)$ & $(3.132)$ \\
female & 8.369 & 7.616 & 7.034 \\
& $(7.749)$ & $(6.730)$ & $(6.274)$ \\
mixed & 35.343 & -1.424 & -2.351 \\
& $(67.942)$ & $(7.368)$ & $(3.469)$ \\
mixed $\times$ female & -6.872 & -1.868 & \\
CS $\times$ mixed & $(9.432)$ & $(11.302)$ & \\
& -51.183 & & \\
Num. of subjects & $(99.935)$ & & \\
Num. of obs. & 284 & 284 & 284 \\
$* p<0.05, * * p<0.01, * * *$ & $p<0.001$ & & \\
& 4190 & 4190 & 4190 \\
\hline
\end{tabular}

Table IV: Average mispricing by low CS (bottom tertile) and high CS (top tertile) traders according to gender and market composition.

\begin{tabular}{lccc}
\multicolumn{3}{c}{ low CS traders } & \\
\hline \hline & Women & Men & $p$-value \\
\hline $\begin{array}{l}\text { Single-gender } \\
\text { markets }\end{array}$ & 0.374 & 0.198 & 0.418 \\
\hline $\begin{array}{l}\text { Mixed-gender } \\
\text { markets }\end{array}$ & 0.130 & 0.064 & 0.425 \\
\hline$p$-value & 0.008 & 0.010 & \\
\hline
\end{tabular}

\begin{tabular}{lccc}
\multicolumn{4}{c}{ high CS traders } \\
\hline & Women & Men & $p$-value \\
\hline $\begin{array}{l}\text { Single-gender } \\
\text { markets }\end{array}$ & 0.082 & 0.084 & 0.373 \\
\hline $\begin{array}{l}\text { Mixed-gender } \\
\text { markets }\end{array}$ & 0.033 & 0.047 & 0.527 \\
\hline$p$-value & 0.590 & 0.204 & \\
\hline
\end{tabular}

Note: $p$-values from pairwise Mann-Whitney $U$-tests

nificant for both male and female traders. High CS traders (with CS scores in the top third of our sample) exhibit lower mispricing in general but are not significantly affected by the gender composition of the market.

As a final verification, we checked if the distribution of CS in homogeneous-gender markets was different than in mixed-gender markets and found no significance using a Mann-Whitney $U$-test ( $p=0.526$, histograms shown in Figure A.I in the appendix).

Hence, a tentative explanation is that low CS traders, which are the primary source of mispricing in the market, might be motivated to behave more cautiously in a mixed-gender environment, resulting in lower mispricing. This interpretation is further developed in the discussion. 


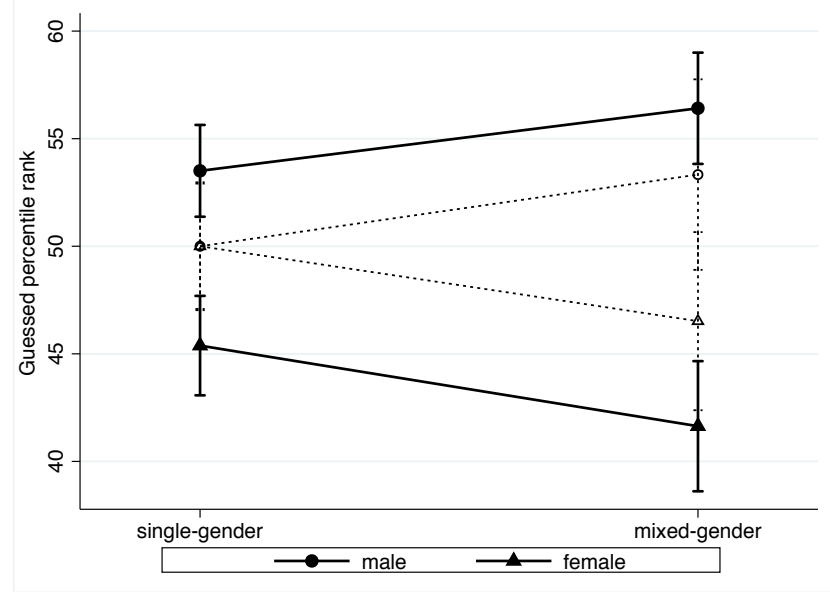

Figure IV: Confidence about relative trading performance. Traders' mean guesses about their percentile rank in the market with respect to their trading profits. Guesses are elicited before the start of the market. Hollow circles connected by dashed lines display actual mean ranks. Whiskers indicate standard errors for each estimate. Confidence levels are significantly higher in men than in women. The difference is significant even in single gender markets $(p=0.0132)$ and particularly large in mixed-gender markets $(p=0.0004)$.

\section{C Gender differences}

In line with the broad evidence in the field, women made significantly more risk-averse choices than men in the lottery task (Mann-Whitney $U$-test, $p=0.0001)^{8}$. Women also made significantly lower guesses about their expected performance relative to the rest of the group in the trading task $(p=0.0001)$, and this difference was greatest in mixed-gender markets, see Figure IV. We found no significant gender differences in trading profits in mixed markets, although men averaged slightly higher (10.91 vs $10.10 ; p=0.194)$. Men also held slightly more assets than women on average in mixed markets $(\approx 11$ vs $\approx 9)$ but the difference was also not significant $(p=0.3)$. Finally, there was no gender difference in scores on the pattern task $(p=0.648)$, but men significantly outperformed women on "hit-15" ( $p=0.0003)$.

Table V summarizes average market activity according to gender in each treatment. We define market activity as the average number of posted or accepted offers per period. Women were more active in homogeneous gender markets than in mixed-gender markets $(p=0.022)$. Men, on the other hand, were slightly more active in mixed markets than in male-only markets, although not significantly $(p=0.421)$. Within mixed-gender markets, men posted significantly more offers than women $(p=0.007)$; however, in terms of trading activity the difference was not significant $(p=0.125)$.

We checked for gender differences in subjects' field of studies and found a similar proportion

\footnotetext{
${ }^{8}$ An alternative way to measure risk aversion is to assume a CRRA utility function and compute the implied range of values of the relative risk aversion coefficients; similar results are obtained with this approach.
} 
of male and female economics or business students $(\approx 12 \%)$. There were no significant differences in the proportion of subjects studying economics or business across our treatments $(15 \%$ in female-only markets, $11 \%$ in mixed markets and $16 \%$ in male-only markets, $\chi^{2}=0.799, p=$ 0.671). Hence, we can rule out the possibility that mixed-gender markets were more stable because they had a higher proportion of economics or business students.

\section{D Evidence from other studies}

Contemporaneously with our study, Eckel and Füllbrunn (2015) conducted seven male-only markets and seven female-only markets using an asset market design with declining (rather than constant) fundamental values similar to that of Smith et al. (1988), and found larger bubbles in male markets. Eckel and Füllbrunn also reviewed 35 other experiments with a declining fundamental value design and found a negative correlation between the magnitude of bubbles and the proportion of female traders in the market.

Their results are much closer to ours than one might expect. Similarly to our study, Eckel and Füllbrunn found no difference in mispricing between male-only and female-only markets: Total Dispersion was very similar in male-only and female-only markets. ${ }^{9}$ Female-only markets exhibited equally large deviations of prices from fundamental values, except these deviations did not form as clear bubble patterns as in male-only markets. Interestingly, their data also show higher trading volumes in female-only markets than in male-only markets, which, as the authors argued, was correlated with mispricing in general rather than with price bubbles. This again highlights the fact that female-only markets did not track fundamentals more accurately than male-only markets in their study, which is consistent with our evidence.

In their meta-analysis, Eckel and Füllbrunn focused on bubble measures and did not examine the relationship between mispricing and gender composition of the market. Using the data

\footnotetext{
${ }^{9}$ Total Dispersion is a similar measure of mispricing to Dispersion in Table I, except the former is not normalized by the number of periods or the magnitude of the fundamental value.
}

Table V: Average market activity of male and female traders in each treatment. Market activity is the average number of posted or accepted offers per period.

\begin{tabular}{lccc} 
& Single-gender markets & Mixed-gender markets & $p$-value \\
\hline Women & 7.68 & 5.99 & 0.022 \\
\hline Men & 6.56 & 6.94 & 0.421 \\
\hline$p$-value & 0.077 & 0.125 &
\end{tabular}

Note: $p$-values from pairwise Mann-Whitney $U$-tests 
reported by the authors, we computed Total Dispersion in the remaining 35 markets reviewed in their study ${ }^{10}$. We compared Total Dispersion in single-gender markets and in mixed-gender markets and found that mixed-gender markets $(N=34)$ exhibited about $24 \%$ lower mispricing than single-gender markets $(N=15)$. Comparison using a Mann-Whitney $U$-test gives a clear statistical significance between the two samples $(p=0.014)$.

To our knowledge, the study by Eckel and Füllbrunn (2015) is the only one, apart from ours, that has investigated the impact of gender-composition of the market on price dynamics of longlived assets. Comparisons between their design and ours - which produces much lower mispricing and fewer bubbles, warrants caution. The declining fundamental values design employed by Eckel and Füllbrunn, originally due to Smith et al. (1988), has been shown to produce severe mispricing across a wide range of environments. One important driver of mispricing in these markets is that subjects often assume constant fundamental values when they are actually declining (Kirchler et al., 2012). In markets with declining fundamental values prices often stay relatively flat at an intermediate value, something which constitutes substantial mispricing even if there is no bubble. For this reason bubble measures in these markets are not necessarily a good indicator of mispricing. Even though their design has important differences with ours, their results are remarkably consistent with our evidence: male-only markets and female-only markets exhibit substantial and comparable mispricing, and mixed-gender markets have significantly lower deviations of prices from fundamental values.

\section{Discussion}

Our primary research question was to test the conjecture that financial markets are more unstable because they are male dominated. We did this by conducting asset market experiments in the laboratory which were either male-only, mixed, or female-only. We rejected the hypothesis of a monotonic relationship between price stability and the proportion of male traders in the market. Instead, we found a "U" shape pattern, with male-only and female-only markets exhibiting substantial and comparable mispricing and instability, and mixed markets displaying prices much closer to fundamental values.

A second hypothesis we tested is that confidence and risk preferences explain market instability. This conjecture is natural, and in view of the known gender difference in confidence

\footnotetext{
${ }^{10}$ Even though Eckel and Füllbrunn $(2015)$ do not report Total Dispersion, it can be computed noting that Total Disperion $=2 \times($ Positive Deviation $)-15 \times($ Average Bias $)$
} 
and risk attitudes, would provide support to the idea that reducing the fraction of males in the market would increase stability. We measured both individual attributes and found that they were not predictive of aggregate price stability. Instead, a third individual attribute, cognitive skills (CS), turned out to have large explanatory power. CS measured subjects' ability to solve two different puzzles which required pattern recognition and strategic thinking respectively. The fact that CS were highly predictive of aggregate mispricing contrasts with the lack of explanatory power of risk preferences and confidence, which underpin the idea that male markets might be more unstable than female markets. This is more significant if we observe that we do find substantial gender differences in confidence and risk attitude, so the assumptions on which the conjecture relies held true in our experiments.

Our finding that higher cognitive skills in the market predict lower deviations of prices from fundamentals and higher price stability is intuitively plausible. It is natural to expect subjects with high CS to make more rational decisions and to outperform traders with low CS in the market. ${ }^{11}$ The result also seems compatible with the notion that mispricing in experimental asset markets can be the product of poor understanding of the environment (Lei and Vesely, 2009; Kirchler et al., 2012; Huber and Kirchler, 2012) or of actual irrationality (Lei et al., 2001; Ackert et al., 2009, 2012), both of which are likely reduced by CS. In this sense, our strategy of controlling for subjects' cognitive ability was very effective in explaining a substantial amount of traders' heterogeneity and variance in aggregate outcomes, something which other researchers might find useful methodologically. ${ }^{12}$

The fact that mixed markets were substantially more stable is consistent with recent field evidence. Hoogendoorn et al. (2013) found that teams with a balanced gender composition outperformed male dominated-teams in a business venture, although the mechanism for this effect remained unclear. We used CS data to forward an explanation of why mixed markets might have been more stable. Dividing traders into low CS and high CS types, we observed a large gap in trading profits in homogeneous-gender markets which was much smaller in mixed-gender markets. Low CS traders made large losses in homogeneous-gender markets by repeatedly buying too high and selling too low, but such deleterious behavior was much more attenuated in

\footnotetext{
${ }^{11}$ This has also been demonstrated in the field recently: Gerardi et al. (2013) found that numerical ability was a reliable predictor of mortgage default on the run-up to the financial crisis; Burks et al. (2009) found that CS predicted ability to make optimal decisions in strategic games and perseverance in job training in a setting with a strong financial penalty for early exit.

${ }^{12}$ Corgnet et al. (2013) also found that subjects with higher scores in a different cognitive task (the Cognitive Reflection Task) earned higher profits and were net sellers when average prices rose above the fundamental value and net buyers when they dipped below the fundamental value.
} 
mixed-gender markets.

A key factor in explaining the aggregate result therefore seems to be that low CS traders behave more cautiously in mixed-gender markets. One possible explanation for this is that mixed-gender environments might be dampening excessive competitive behavior that is induced in single-gender environments. This conjecture is based on previous evidence on the effects of gender mixing on competition and on decision-making under uncertainty. For example, Holm (2000), Sutter et al. (2009) and Castillo et al. (2013) found that the behavior of bargaining partners in homogeneous gender groups was more aggressive and retaliatory than the behavior of partners of the opposite sex, resulting in inefficient outcomes. Similarly, Gneezy et al. (2003), Gneezy and Rustichini (2004) and Niederle and Vesterlund (2007) found that women's willingness to compete was inhibited in mixed-gender environments. More recently, Booth and Nolen (2012a,b) and Booth et al. (2014) found that single-gender environments increased women's willingness to compete and take risks. In particular, Booth and Nolen (2012a,b) elicited lottery choices and willingness to compete in an experiment with boys and girls just under 15 years old and found that girls attending all-girls schools were significantly more risk-taking and willing to compete than girls attending coeducational schools. Girls participating in homogeneous-gender sessions were also more risk-taking than girls participating in mixed-gender sessions.

An alternative explanation is that mixed-gender environments induce low CS traders to scrutinize their own decisions and those of others more than homogenous ones, resulting in more cautios behavior. Levine et al. (2014) conducted asset market experiments with declining fundamental values and found that ethnically homogenous groups exhibited larger mispricing than ethnically diverse ones. The authors relate their findings to the broader evidence in social psychology that homogenous groups foster superficial thinking and are more likely to engender conformity and herding than diverse groups, which in their asset markets translated into higher mispricing.

In our data we also found support for the principle that "boys will be boys": ${ }^{13}$ confidence was higher in males, and the mixed-gender composition enhanced the difference, with female traders becoming less active in these markets. This finding adds further support to previous field evidence showing that men tend to trade more stocks than women (Barber and Odean, 2001; Grinblatt and Keloharju, 2001, 2009) ${ }^{14}$ and that at least part of this difference can be

\footnotetext{
${ }^{13}$ In a field study with this title, Barber and Odean (2001) found that male owners of a brokerage account were more likely to overtrade than their female counterparts. The authors argued that such difference was most likely due to men's tendency towards overconfidence.

${ }^{14}$ Whereas Barber and Odean (2001) and Grinblatt and Keloharju (2009) found an overall clear gender differ-
} 
explained by confidence. In mixed-gender markets, a similar difference in male and female trading activity was reported in previous experimental studies (Biais et al., 2005; Fellner and Maciejovsky, 2007).

To our knowledge, the only study to investigate the effect of gender composition on price dynamics in asset markets is contemporaneous work by Eckel and Füllbrunn (2015). They conducted seven male-only markets and seven female-only markets using an asset market design with declining (rather than constant) fundamental values similar to that of Smith et al. (1988), and found larger and more frequent bubbles in male markets. They also reviewed 35 markets reported in previous studies and found a negative correlation between the proportion of women in the market and bubble measures. We tested the hypothesis that mixed-gender markets exhibit lower mispricing than single-gender markets in the data reported in Eckel and Füllbrunn (2015), and found that this was indeed the case. Remarkably, we reproduced exactly the same "U" shape pattern in their data: male-only and female-only markets had similar mispricing, whereas mixed-gender markets exhibited significantly lower deviations of prices from fundamental values.

One limitation of our results is that we cannot say whether, for example, a market with $20 \%$ female traders would be as stable as one with $50 \%$ or $80 \%$ female traders. Most of our mixed markets were close to a 50-50 mix, and our sample size does not allow us to answer this more subtle question. Since there are already between 10 to $20 \%$ female traders operating in Wall Street, one could argue that the benefits of female participation have already been fully accrued. However, the environment in a trading floor is more likely to resemble a male-only market than a mixed one. Firstly because a minority of women are unlikely to change the dominant male culture of the business. Secondly, because selective pressures in the industry may currently favor women with the most stereotypically male attitudes with regards to risk-taking, confidence and competitiveness.

Financial stability is desirable, but difficult to achieve, and might require more than financial regulation. The present study shows that stability might be improved by a rich variety of factors. In our data, the size of the effects of gender and cognitive skills are large and comparable, suggesting additional potential benefits from policies aimed at boosting the participation of highly capable women in financial markets ${ }^{15}$.

ence in the propensity to trade, Grinblatt and Keloharju (2001) analyzed investors' buy, sell and hold decisions and only found a gender difference on the propensity to buy stocks.

${ }^{15}$ For example, Balafoutas and Sutter (2012) and Niederle et al. (2013) find that affirmative action policies can help to overcome the gender gap in willingness to compete, thereby increasing participation of highly capable women. 


\section{Appendix}

Table A.I: List of binary choices in the lottery task

\begin{tabular}{ccc} 
& Safe option & Risky option \\
\hline 1. & $£ 2.50$ & $£ 0$ or $£ 10$ with equal probability \\
2. & $£ 2.75$ & $£ 0$ or $£ 10$ with equal probability \\
3. & $£ 3.00$ & $£ 0$ or $£ 10$ with equal probability \\
4. & $£ 3.25$ & $£ 0$ or $£ 10$ with equal probability \\
5. & $£ 3.50$ & $£ 0$ or $£ 10$ with equal probability \\
6. & $£ 3.75$ & $£ 0$ or $£ 10$ with equal probability \\
7. & $£ 4.00$ & $£ 0$ or $£ 10$ with equal probability \\
8. & $£ 4.25$ & $£ 0$ or $£ 10$ with equal probability \\
9. & $£ 4.50$ & $£ 0$ or $£ 10$ with equal probability \\
10. & $£ 4.75$ & $£ 0$ or $£ 10$ with equal probability \\
11. & $£ 5.00$ & $£ 0$ or $£ 10$ with equal probability \\
12. & $£ 5.25$ & $£ 0$ or $£ 10$ with equal probability \\
13. & $£ 5.50$ & $£ 0$ or $£ 10$ with equal probability \\
14. & $£ 5.75$ & $£ 0$ or $£ 10$ with equal probability \\
15. & $£ 6.00$ & $£ 0$ or $£ 10$ with equal probability \\
\hline
\end{tabular}

Table A.II: Market size and percentage of female traders in each session

\begin{tabular}{ccc}
\hline session & \% women & size \\
1 & 0 & 10 \\
2 & 0 & 8 \\
3 & 0 & 10 \\
4 & 0 & 10 \\
5 & 0 & 10 \\
6 & 0 & 9 \\
7 & 0 & 10 \\
8 & 0 & 10 \\
9 & 0 & 10 \\
10 & 0 & 8 \\
\hline
\end{tabular}

\begin{tabular}{ccc}
\hline session & \% women & size \\
11 & 100 & 10 \\
12 & 100 & 10 \\
13 & 100 & 10 \\
14 & 100 & 9 \\
15 & 100 & 10 \\
16 & 100 & 10 \\
17 & 100 & 10 \\
18 & 100 & 10 \\
19 & 100 & 10 \\
20 & 100 & 10 \\
\hline
\end{tabular}

\begin{tabular}{ccc}
\hline session & \% women & size \\
21 & 17 & 6 \\
22 & 40 & 10 \\
23 & 40 & 10 \\
24 & 43 & 7 \\
25 & 50 & 10 \\
26 & 50 & 10 \\
27 & 50 & 10 \\
28 & 60 & 10 \\
29 & 63 & 8 \\
30 & 67 & 9 \\
\hline
\end{tabular}




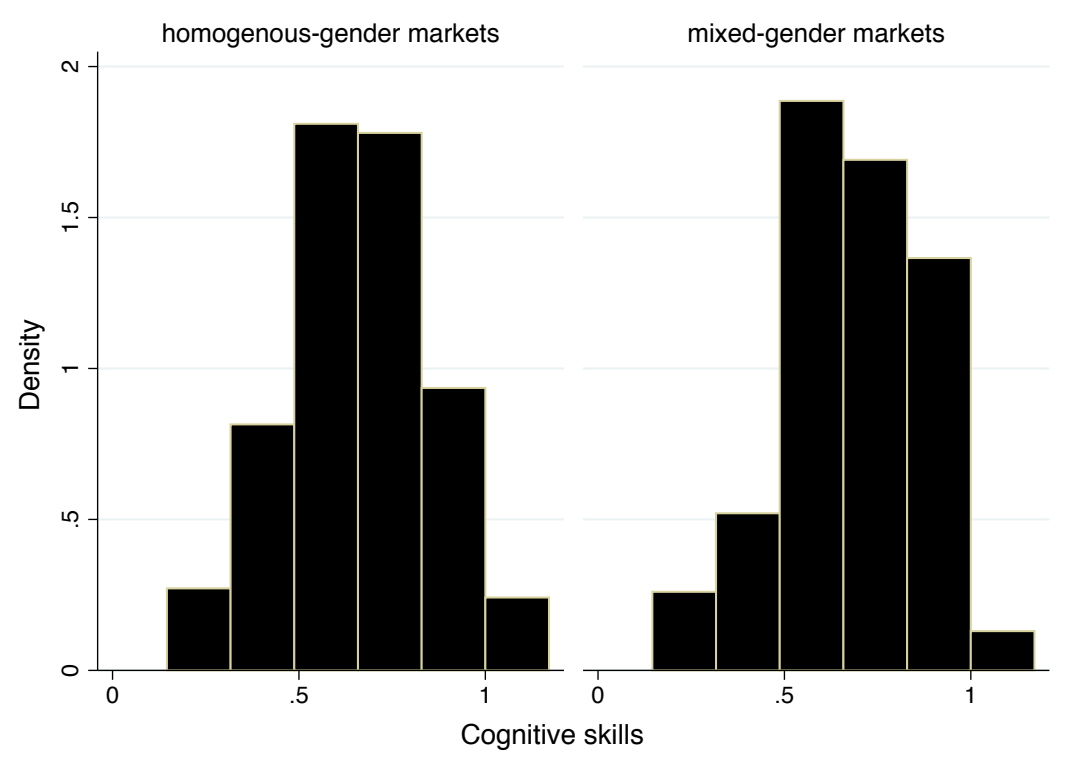

Figure A.I: Histograms of cognitive skills scores in homogeneous-gender markets and mixedgender markets. No significant differences found ( $p=0.526$, Mann-Whitney $U$-test) 


\section{References}

Ackert L.F., Charupat N., Deaves R., Kluger B.D., 2009. Probability judgment error and speculation in laboratory asset market bubbles. Journal of Financial and Quantitative Analysis $44,719-744$.

Ackert L.F., Kluger B.D., Qi L., 2012. Irrationality and beliefs in a laboratory asset market: Is it me or is it you? Journal of Economic Behavior \& Organization 84, 278-291.

Arano K., Parker C., Terry R., 2010. Gender-based risk aversion and retirement asset allocation. Economic Inquiry 48, 147-155.

Atkinson S.M., Baird S.B., Frye M.B., 2003. Do female mutual fund managers manage differently? Journal of Financial Research 26, 1-18.

Bajtelsmit V.L., VanDerhei J.L., 1997. Risk aversion and pension investment choices. In: M.S. Gordon, O.S. Mitchell, M.M. Twinney (Eds.), Positioning pensions for the twenty-first century, 45-66. University of Pennsylvania Press.

Balafoutas L., Sutter M., 2012. Affirmative action policies promote women and do not harm efficiency in the laboratory. Science 335, 579-82.

Barber B.M., Odean T., 2001. Boys will be boys: Gender, overconfidence, and common stock investment. The Quarterly Journal of Economics 116, 261-292.

Beckmann D., Menkhoff L., 2008. Will women be women? analyzing the gender difference among financial experts. Kyklos 61, 364-384.

Bertrand M., 2011. New perspectives on gender. volume 4, Part B of Handbook of Labor Economics, 1543 - 1590. Elsevier.

Biais B., Hilton D., Mazurier K., Pouget S., 2005. Judgemental overconfidence, self-monitoring, and trading performance in an experimental financial market. The Review of economic studies $72,287-312$.

Booth A.L., Cardona-Sosa L., Nolen P., 2014. Gender differences in risk aversion: do single-sex environments affect their development? Journal of Economic Behavior \& Organization 99, $126-154$. 
Booth A.L., Nolen P., 2012a. Choosing to compete: How different are girls and boys? Journal of Economic Behavior \& Organization 81, 542-555.

Booth A.L., Nolen P., 2012b. Gender differences in risk behaviour: does nurture matter? The Economic Journal 122, F56-F78.

Burks S.V., Carpenter J.P., Goette L., Rustichini A., 2009. Cognitive skills affect economic preferences, strategic behavior, and job attachment. Proceedings of the National Academy of Sciences of the United States of America 106, 7745-50.

Buser T., Niederle M., Oosterbeek H., forthcoming. Gender, competitiveness and career choices. The Quarterly Journal of Economics 129.

Byrnes J.P., Miller D.C., Schafer W.D., 1999. Gender differences in risk taking: A meta-analysis. Psychological Bulletin 125, 367-383.

Cárdenas J.C., Dreber A., von Essen E., Ranehill E., 2012. Gender differences in competitiveness and risk taking: Comparing children in colombia and sweden. Journal of Economic Behavior \& Organization 83, 11 - 23. Gender Differences in Risk Aversion and Competition.

Castillo M., Petrie R., Torero M., Vesterlund L., 2013. Gender differences in bargaining outcomes: A field experiment on discrimination. Journal of Public Economics 99, 35 - 48.

Charness G., Gneezy U., 2012. Strong Evidence for Gender Differences in Risk Taking. Journal of Economic Behavior \& Organization 83, 50-58.

Coates J.M., Gurnell M., Rustichini A., 2009. Second-to-fourth digit ratio predicts success among high-frequency financial traders. Proceedings of the National Academy of Sciences of the United States of America 106, 623-8.

Coates J.M., Herbert J., 2008. Endogenous steroids and financial risk taking on a london trading floor. Proceedings of the National Academy of Sciences of the United States of America 105, $6167-72$.

Corgnet B., Herán Gonzalez R., Kujal P., Porter D., 2013. The effect of earned vs. house money on price bubble formation in experimental asset markets. Working paper .

Croson R., Gneezy U., 2009. Gender differences in preferences. Journal of Economic Literature $47,448-474$. 
Datta Gupta N.D., Poulsen A., Villeval M.C., 2013. Gender matching and competitiveness: experimental evidence. Economic Inquiry 51, 816-835.

Deaux K., Farris E., 1977. Attributing causes for one's own performance: The effects of sex, norms, and outcome. Journal of Research in Personality 11, 59-72.

Dreber A., vOn EssEn E., Ranehill E., 2011. Outrunning the gender gapboys and girls compete equally. Experimental Economics 14, 567-582.

Dwyer P.D., Gilkeson J.H., List J.A., 2002. Gender differences in revealed risk taking: evidence from mutual fund investors. Economics Letters 76, 151-158.

Eckel C.C., Füllbrunn S., 2015. Thar'she'blows? gender, competition, and bubbles in experimental asset markets. American Economic Review (forthcoming) .

Eckel C.C., Grossman P.J., 2008. Men, women and risk aversion: Experimental evidence. volume 1 of Handbook of experimental economics results, 1061-1073. Elsevier.

Estes R., Hosseini J., 1988. The gender gap on Wall Street: an empirical analysis of confidence in investment decision making. The Journal of Psychology 122, 577-590.

Fellner G., Maciejovsky B., 2007. Risk attitude and market behavior: Evidence from experimental asset markets. Journal of Economic Psychology 28, 338-350.

Gerardi K., Goette L., Meier S., 2013. Numerical ability predicts mortgage default. Proceedings of the National Academy of Sciences 110, 11267-11271.

Gneezy U., Leonard K.L., List J.A., 2009. Gender differences in competition: Evidence from a matrilineal and a patriarchal society. Econometrica 77, 1637-1664.

Gneezy U., Niederle M., Rustichini A., 2003. Performance in competitive environments: Gender differences. The Quarterly Journal of Economics 118, 1049-1074.

Gneezy U., Rustichini A., 2004. Gender and competition at a young age. American Economic Review 94, 377-381.

Green C., Jegadeesh N., Tang Y., 2009. Gender and job performance: Evidence from wall street. Financial Analysts Journal 65, 65-78. 
Grinblatt M., Keloharju M., 2001. What makes investors trade? The Journal of Finance 56, $589-616$.

Grinblatt M., Keloharju M., 2009. Sensation seeking, overconfidence, and trading activity. The Journal of Finance 64, 549-578.

Günther C., Ekinci N.A., Schwieren C., Strobel M., 2010. Women can’t jump? an experiment on competitive attitudes and stereotype threat. Journal of Economic Behavior \& Organization $75,395-401$.

Holm H.J., 2000. Gender-based focal points. Games and Economic Behavior 32, $292-314$.

Holt C.A., Laury S.K., 2002. Risk aversion and incentive effects. American Economic Review $92,1644-1655$.

Hoogendoorn S., Oosterbeek H., Van Praag M., 2013. The impact of gender diversity on the performance of business teams: Evidence from a field experiment. Management Science 59, $1514-1528$.

Huber J., Kirchler M., 2012. The impact of instructions and procedure on reducing confusion and bubbles in experimental asset markets. Experimental Economics 15, 89-105.

Iriberri N., Rey-Biel P., 2013. Lets (not) talk about sex: Gender awareness and stereotype-threat on performance under competition. Working paper.

Jianakoplos N.A., Bernasek A., 1998. Are women more risk averse? Economic inquiry 36, 620-630.

Kirchler M., Huber J., Stöckl T., 2012. Thar she bursts: Reducing confusion reduces bubbles. American Economic Review 102, 865-83.

Lei V., Noussair C.N., Plott C.R., 2001. Nonspeculative bubbles in experimental asset markets: Lack of common knowledge of rationality vs. actual irrationality. Econometrica 69, 831-859.

Lei V., Vesely F., 2009. Market efficiency: Evidence from a no-bubble asset market experiment. Pacific Economic Review 14, 246-258.

Levine S.S., Apfelbaum E.P., Bernard M., Bartelt V.L., Zajac E.J., Stark D., 2014. Ethnic diversity deflates price bubbles. Proceedings of the National Academy of Sciences 1852418529. 
Lundeberg M.A., Fox P.W., Punćcohaŕ J., 1994. Highly confident but wrong: Gender differences and similarities in confidence judgments. Journal of educational psychology 86, 114-121.

Madden J.F., 2012. Performance-support bias and the gender pay gap among stockbrokers. Gender \& Society 26, 488-518.

Niederle M., Segal C., Vesterlund L., 2013. How costly is diversity? affirmative action in light of gender differences in competitiveness. Management Science 59, 1-16.

Niederle M., Vesterlund L., 2007. Do women shy away from competition? do men compete too much? The Quarterly Journal of Economics 122, 1067-1101.

Niederle M., Vesterlund L., 2011. Gender and competition. Annual Review of Economics 3, $601-630$.

Noussair C., Robin S., Ruffieux B., 2001. Price bubbles in laboratory asset markets with constant fundamental values. Experimental Economics 4, 87-105.

Palan S., 2013. A review of bubbles and crashes in experimental asset markets. Journal of Economic Surveys 27, 570-588.

Porter D.P., Smith V.L., 2003. Stock market bubbles in the laboratory. Journal of Behavioral Finance 4, 7-20.

Prügl E., 2012. "If Lehman Brothers had been Lehman Sisters...": gender and myth in the aftermath of the financial crisis. International Political Sociology 6, 21-35.

Raven J.C., 2000. Raven's Standard Progressive Matrices (SPM) and Raven's Standard Progressive Matrices Plus (SPM Plus). Pearson.

Sapienza P., Zingales L., Maestripieri D., 2009. Gender differences in financial risk aversion and career choices are affected by testosterone. Proceedings of the National Academy of Sciences of the United States of America 106, 15268-73.

Shurchkov O., 2012. Under pressure: Gender differences in output quality and quantity under competition and time constraints. Journal of the European Economic Association 10, 11891213.

Smith V.L., Suchanek G.L., Williams A.W., 1988. Bubbles, crashes, and endogenous expectations in experimental spot asset markets. Econometrica 56, 1119-1151. 
Soll J.B., Klayman J., 2004. Overconfidence in interval estimates. Journal of Experimental Psychology: Learning, Memory, and Cognition 30, 299-314.

Stöckl T., Huber J., Kirchler M., 2010. Bubble measures in experimental asset markets. Experimental Economics 13, 284-298.

Sundén A.E., Surette B.J., 1998. Gender differences in the allocation of assets in retirement savings plans. The American Economic Review 88, 207-211.

Sutter M., Bosman R., Kocher M.G., Winden F., 2009. Gender pairing and bargaining - beware the same sex! Experimental Economics 12, 318-331. 


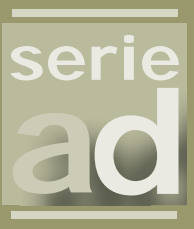

\section{I vie}

Guardia Civil, 22 - Esc. 2, 19

46020 Valencia - Spain

Phone: +34 963190050

Fax: +34 963190055

Website: www.ivie.es

E-mail: publicaciones@ivie.es 